\title{
ANALISIS PERBANDINGAN ABNORMAL RETURN DAN LIKUIDITAS SAHAM SEBELUM DAN SESUDAH STOCK SPLIT PADA PERUSAHAAN YANG TERDAFTAR DI BURSA EFEK INDONESIA PERIODE 2010-2015
}

\author{
Cindy Hadiwijaya \\ Program Studi Magister Manajemen Universitas Tarumanagara \\ cindy_juju_hadiwijaya@yahoo.co.uk \\ Indra Widjaja \\ Program Studi Magister Manajemen Universitas Tarumanagara
}

\begin{abstract}
This research aims to find out whether there is a significant difference in abnormal return and liquidity of shares before and after stock split for companies listed in Indonesian Stock Exchange during 2010-2015. 46 samples were obtained using purposive sampling method. The observation period is 10 days before and after stock split announcement. Hypothesis was tested by using Wilcoxon Signed Rank Test with significant level of 0.05. The result of this research shows that there is a significant difference in abnormal return before and after stock split, while there is no significant difference of share's liquidity before and after stock split.
\end{abstract}

Keywords : Stock Split, Abnormal Return, Liquidity of Shares.

\section{PENDAHULUAN}

Pasar keuangan merupakan pasar yang menyediakan instrumen keuangan. Berdasarkan jenis instrumen yang diperdagangkan, terdapat dua jenis pasar keuangan yaitu pasar uang dan pasar modal. Pasar uang memperdagangkan instrumen keuangan jangka pendek yaitu yang memiliki masa jatuh tempo kurang dari satu tahun, contohnya adalah deposito berjangka. Sedangkan pasar modal memperdagangkan instrumen keuangan jangka panjang yaitu yang memiliki masa jatuh tempo lebih dari satu tahun, contohnya adalah saham.

Sama halnya dengan pengertian pasar pada umumnya, pasar modal sendiri merupakan tempat yang mempertemukan dua pihak. Kedua pihak yang dimaksud yaitu perusahaan yang ingin mendapatkan sumber pembiayaan tambahan dan para investor yang ingin menginvestasikan kelebihan dananya. Tujuan utama yang ingin dicapai oleh para investor ketika berinvestasi dalam bentuk saham adalah return.

Untuk memperoleh return yang optimal, investor membutuhkan informasi sebagai dasar pertimbangannya dalam membuat suatu keputusan investasi. Berdasarkan jenisnya, informasi yang dapat digunakan oleh investor dapat dibedakan menjadi dua yaitu informasi tertutup (private information) dan informasi terbuka (public information). Contoh dari informasi terbuka adalah laporan keuangan perusahaan dan pengumuman atas aksi perusahaan (corporate action).

Kedua contoh informasi terbuka tersebut memiliki orientasi yang berbeda. Laporan keuangan memberikan informasi historis mengenai hasil kinerja yang sudah dicapai oleh perusahaan di masa lampau, sedangkan pengumuman atas corporate action cenderung 
memberikan informasi tentang rencana serta keyakinan keyakinan perusahaan atas kinerja yang diharapkan akan tercapai pada masa yang akan datang.

Selain kinerja perusahaan yang baik, salah satu faktor penting yang dapat mempengaruhi keputusan investor dalam membeli saham suatu perusahaan adalah harga pasar saham itu sendiri. Investor yang berfokus pada keuntungan jangka pendek akan lebih tertarik untuk membeli saham yang likuid diperdagangkan karena dapat dengan mudah dijual kembali demi mendapatkan capital gain. Sesuai dengan hukum permintaan, apabila harga pasar suatu saham terlalu rendah maka permintaan atas saham tersebut akan mengalami peningkatan dan sebaliknya apabila harga pasar suatu saham terlalu tinggi maka permintaan atas saham tersebut pasti akan mengalami penurunan.

Cara yang dapat ditempuh oleh perusahaan untuk mengatasi masalah tingginya harga pasar saham tersebut adalah dengan melakukan corporate action berupa pemecahan saham atau yang seringkali disebut stock split. Dengan dilakukannya stock split maka harga per lembar saham akan mengalami penurunan diiringi dengan peningkatan jumlah lembar saham yang beredar pada rasio tertentu yang besarnya proporsional sehingga hasilnya tidak akan mengubah kapitalisasi saham secara keseluruhan.

Di pasar modal Indonesia peristiwa stock split sendiri cukup sering terjadi, tercatat sepanjang tahun 2010-2015 terdapat 77 peristiwa stock split. Hal ini mengindikasikan bahwa stock split merupakan salah satu alat penting bagi perusahaan dalam praktik pasar modal walaupun secara teoritis stock split tidak mempengaruhi aliran kas perusahaan dan tidak menambah nilai kapitalisasi saham perusahaan.

Terdapat dua teori yang mendominasi literatur tentang stock split yaitu signalling theory dan trading range theory. Berdasarkan signalling theory, stock split diyakini sebagai cara perusahaan dalam menyampaikan sinyal positif kepada investor bahwa kinerja perusahaan kedepannya diyakini akan terus meningkat dan memberikan return yang menguntungkan. Berdasarkan trading range theory, perusahaan melakukan stock split karena harga sahamnya dirasakan sudah terlalu tinggi dan menyebabkan sahamnya tidak likuid, hal ini berkaitan dengan tingkat kemampuan investor yang berbeda-beda.

Namun sampai sekarang stock split masih menjadi suatu fenomena ekonomi yang diperdebatkan oleh para ekonom karena adanya ketidakonsistenan antara kedua teori diatas dengan reaksi aktual para investor di pasar modal. Hal ini dibuktikan dari berbagai penelitian yang telah dilakukan oleh peneliti-peneliti sebelumnya menunjukkan hasil yang bervariasi.

Penelitian yang dilakukan oleh Muharam dan Sakti (2008) mendapatkan hasil terdapat perbedaan yang signifikan pada abnormal return sebelum dan sesudah stock split sedangkan penelitian yang dilakukan oleh Akhmad dan Ramadiyansari (2013) mendapatkan hasil sebaliknya yaitu tidak terdapat perbedaan yang signifikan pada abnormal return sebelum dan sesudah stock split. Penelitian yang dilakukan oleh Safitri dan Widjanarko (2009) mendapatkan hasil terdapat perbedaan yang signifikan pada likuiditas saham sebelum dan sesudah stock split sedangkan penelitian yang dilakukan oleh Hernoyo (2013) mendapatkan hasil sebaliknya yaitu tidak terdapat perbedaan yang signifikan pada likuiditas saham sebelum dan sesudah stock split.

Oleh sebab itu, maka tujuan dari penelitian ini adalah untuk mengetahui apakah terdapat perbedaan yang signifikan pada abnormal return dan likuiditas saham sebelum dan sesudah stock split pada perusahan yang terdaftar di Bursa Efek Indonesia periode 20102015.

\section{LANDASAN TEORI}

Corporate action. Corporate action adalah suatu kegiatan yang dilakukan oleh perusahaan dan mempunyai kemungkinan mempengaruhi harga saham di bursa efek. Keputusan 
perusahaan untuk melakukan suatu aksi didasarkan pada beberapa tujuan tertentu, misalnya untuk meningkatkan modal dan untuk meningkatkan likuiditas perdagangan saham. Corporate action yang seringkali dilakukan di pasar modal adalah stock split, right issue, saham bonus dan pembagian dividen (Rusliati dan Farida, 2010).

Stock Split. Menurut Akhmad dan Ramadiyansari (2013), stock split adalah penurunan nilai nominal per lembar saham yang mengakibatkan bertambahnya jumlah saham yang beredar sesuai dengan faktor pemecah (split factors). Split factors diartikan sebagai perbandingan antara jumlah saham yang beredar setelah pemecahan dengan saham yang beredar sebelum pemecahan.

Pada dasarnya terdapat dua jenis pemecahan saham yang dapat dilakukan yaitu pemecahan naik (split-up) dan pemecahan turun (split-down atau reverse split). Pemecahan saham naik adalah penurunan nilai nominal per lembar saham yang mengakibatkan bertambahnya jumlah saham yang beredar, misalnya pemecahan saham dengan faktor 2:1, 3:1 dan 4:1. Sedangkan pemecahan turun adalah peningkatan nilai nominal per lembar saham dan mengurangi jumlah saham yang beredar, misalnya pemecahan saham dengan faktor 1:2, 1:3, dan 1:4 (Ewijaya dan Indriantoro, 1999).

Signalling Theory. Menurut teori ini, stock split yang merupakan salah satu bentuk corporate action merupakan pemberian sinyal yang positif kepada investor bahwa kinerja perusahaan kedepannya diyakini akan terus meningkat dan memberikan return yang menguntungkan. Stock split seharusnya merupakan sinyal yang valid karena tidak semua perusahaan dapat melakukannya, hanya perusahaan yang memiliki kinerja baik saja yang dapat melakukannya karena biaya yang ditimbulkan dari aktivitas stock split akan ditanggung oleh perusahaan, contohnya seperti biaya penerbitan saham dan biaya perijinan padahal stock split itu sendiri tidak memberikan tambahan arus kas dan tidak mempengaruhi nilai kapitalisasi saham (Winarso, 2005).

Dapat disimpulkan bahwa berdasarkan teori ini faktor kinerja perusahaan yang merupakan motivasi utama perusahaan melakukan stock split. Oleh sebab itu, stock split yang dilakukan oleh perusahaan akan diinterpretasikan oleh investor sebagai sinyal positif dimana hal tersebut akan ditunjukkan dengan adanya abnormal return di sekitar tanggal pengumuman stock split (Jogiyanto, 2008).

Trading Range Theory. Menurut teori ini, stock split digunakan sebagai alat untuk mengatur kembali harga saham pada kisaran yang diinginkan oleh perusahaan sehingga dapat menciptakan pasar yang lebih luas karena semakin memungkinkan bagi investor untuk membeli saham tersebut (Copeland, 1979). Harga saham yang terlalu tinggi akan menyebabkan permintaan terhadap pembelian saham tersebut menurun dan pada akhirnya dapat menyebabkan harga saham perusahaan tersebut menjadi tidak fluktuatif lagi. Penurunan permintaan tersebut dapat disebabkan karena tidak semua investor tertarik untuk membeli saham dengan harga yang terlalu tinggi, terutama investor perorangan yang memiliki keterbatasan dana, yang terjadi kemudian adalah para investor tersebut akan berbalik untuk membeli saham perusahaan lain (Asriningsih, 2015). Oleh sebab itu, penting bagi perusahaan untuk melakukan stock split untuk membuat harga sahamnya berada pada rentang harga yang optimal sehingga banyak orang dapat memperjualbelikannya sehingga akhirnya akan meningkatkan likuiditas perdagangan saham tersebut (Hikmah, 2010).

Efficient Market Hypothesis. Konsep ini dikemukakan dan dipopulerkan oleh Eugene Fama pada tahun 1970. Suatu pasar dikatakan efisien apabila tidak seorang pun, baik investor individu maupun investor institusi, mampu memperoleh return tidak normal (abnormal 
return), setelah disesuaikan dengan risiko, dengan menggunakan strategi perdagangan yang ada. Artinya harga-harga yang terbentuk di pasar merupakan cerminan dari informasi yang ada. Masing-masing kelompok informasi tersebut mencerminkan sejauh mana tingkat efisiensi suatu pasar yang terbagi menjadi tiga jenis, antara lain: (1) Pasar efisien bentuk lemah; (2) Pasar efisien bentuk bentuk setengah kuat dan (3) Pasar efisien bentuk kuat.

Menurut konsep pasar efisien bentuk semi-kuat, investor tidak akan mampu untuk memperoleh abnormal return dengan menggunakan informasi publik. Dengan kata lain, analisis terhadap laporan keuangan dan pengumuman atas corporate action tidak memberikan manfaat apa-apa. Ide dari pandangan ini adalah bahwa sekali informasi tersebut tersebar di pasar dan menjadi konsumsi umum, maka semua investor akan bereaksi dengan cepat dan mendorong harga untuk segera mencerminkan informasi tersebut.

Event study (studi peristiwa). Event study merupakan studi yang mempelajari reaksi pasar terhadap suatu peristiwa yang informasinya telah dipublikasikan, misalkan stock split. Studi ini seringkali digunakan untuk menguji pasar efisien bentuk semi kuat. Reaksi pasar ditunjukkan dengan adanya perubahan pada sekuritas, misalkan perubahan harga, perubahan volume perdagangan saham dan abnormal return (Jogiyanto, 2014).

Return. Jogiyanto (2008) mengemukakan bahwa return yang diperoleh dari investasi dapat dibagi menjadi dua jenis yaitu return realisasi (actual return) dan return ekspektasi (expected return). Actual return merupakan return yang telah didapatkan dari investasi yang dapat dihitung dengan mengurangi harga saham pada periode sekarang dibandingkan dengan periode sebelumnya, sedangkan expected return merupakan return yang diharapkan akan diperoleh dari investasi yang dihitung menggunakan probabilitas kejadian dari tingkat keuntungan. Salah satu model yang dapat digunakan untuk yaitu market adjusted model yang menganggap penduga yang terbaik untuk mengestimasi return suatu sekuritas adalah return indeks pasar pada saat tersebut.

Selisih antara actual return dengan expected return disebut dengan return tidak normal (abnormal return) atau biasa juga disebut excess return. Besarnya return yang akan diterima investor sehubungan dengan adanya peristiwa stock split diukur menggunakan abnormal return. Abnormal return yang positif setelah dilakukannya stock split menandakan bahwa investor memperoleh keuntungan diatas normal, sebaliknya abnormal return yang negatif setelah dilakukannya stock split menandakan bahwa investor memperoleh keuntungan dibawah normal.

Likuiditas Saham. Likuiditas saham adalah kemampuan suatu saham untuk terjual dalam jangka waktu singkat tanpa adanya pengurangan harga secara signifikan (Horne dan Wachowicz, 2005). Volume perdagangan saham (trading volume activity) merupakan rasio antara jumlah lembar saham yang diperdagangkan pada waktu tertentu terhadap jumlah saham yang beredar pada waktu tertentu (Husnan, sebagaimana yang dikutip oleh Akhmad dan Ramadiyansari, 2013). Semakin banyak investor yang melakukan transaksi terhadap suatu saham maka volume perdagangan saham tersebut akan meningkat (Copeland, 1979). Volume perdagangan saham merupakan salah satu indikator yang dapat digunakan untuk melihat reaksi pasar terhadap kejadian atau informasi yang berkaitan dengan suatu saham (Savitri dan Martani, 2006).

\section{Hipotesis penelitian.}

H1: Terdapat perbedaan yang signifikan pada abnormal return saham sebelum dan sesudah stock split. 
H2: Terdapat perbedaan yang signifikan pada likuiditas saham sebelum dan sesudah stock split.

\section{METODE PENELITIAN}

Jenis dan Periode Penelitian. Penelitian ini merupakan studi peristiwa (event study), yaitu penelitian yang mempelajari reaksi pasar terhadap suatu peristiwa yang informasinya dipublikasikan sebagai suatu pengumuman. Penelitian ini mengamati reaksi pasar yang tercermin dalam abnormal return dan likuiditas saham terhadap peristiwa stock split. Penelitian ini juga merupakan penelitian historis karena berusaha untuk memperoleh pemahaman atas peristiwa yang sudah terjadi di masa lampau yaitu peristiwa stock split yang terjadi selama tahun 2010-2015.

Populasi dan Sampel Penelitian. Populasi dalam penelitian ini adalah seluruh perusahaan yang terdaftar di Bursa Efek Indonesia dan melakukan stock split selama tahun 2010-2015 yaitu sebanyak 77 perusahaan. Pengambilan sampel berjumlah 46 perusahaan menggunakan teknik purposive sampling karena penentuan sampel didasarkan kepada kriteria tertentu yang telah ditentukan oleh penulis, antara lain sebagai berikut:

1. Perusahaan yang hanya melakukan corporate action berupa stock split sepanjang event period.

2. Jenis stock split yang dilakukan adalah pemecahan saham naik (split-up).

3. Perusahaan memiliki kelengkapan data yang diperlukan dalam penelitian.

4. Saham perusahaan aktif diperdagangkan.

5. Perusahaan masih terdaftar di BEI sampai diadakannya penelitian ini yaitu tahun 2017.

Obyek Penelitian. Terdapat dua obyek dalam penelitian ini yaitu abnormal return dan likuiditas saham.

Sumber dan Pengumpulan Data. Jenis data yang digunakan dalam penelitian ini adalah data sekunder, yaitu data yang sebelumnya telah dikumpulkan atau telah dipublikasikan oleh pihak lain. Data yang digunakan juga merupakan data kuantitatif yang diperoleh dari perpustakaan dan internet.

Event period. Periode peristiwa (event period) yang digunakan dalam penelitian ini adalah 20 hari bursa di sekitar peristiwa stock split yang terdiri dari 10 hari sebelum peristiwa (preevent) dan 10 hari setelah peristiwa (post-event).

Stock Split. Tanggal stock split yang digunakan sebagai patokan untuk perhitungan abnormal return adalah tanggal pengumuman stock split sedangkan untuk perhitungan likuiditas saham adalah tanggal dilakukannya stock split.

\section{Abnormal Return.}

Adapun cara untuk menghitung abnormal return dalam penelitian ini adalah:

1. Menghitung actual return

$$
\mathrm{Ri}_{\mathrm{i}, \mathrm{t}}=\frac{\mathrm{P}_{\mathrm{i}, \mathrm{t}-\mathrm{Pi}, \mathrm{t}-1}}{\mathrm{Pi}_{\mathrm{i}, \mathrm{t}-1}}
$$

Keterangan:

$\mathrm{R}_{\mathrm{i}, \mathrm{t}} \quad$ : return saham i pada hari ke $\mathrm{t}$

$\mathrm{P}_{\mathrm{i}, \mathrm{t}} \quad$ : harga saham i pada hari ke $\mathrm{t}$

$\mathrm{P}_{\mathrm{i}, \mathrm{t}-1} \quad$ : harga saham i pada hari ke t-1 
2. Menghitung expected return

$$
\mathrm{Rm}, \mathrm{t}=\frac{\text { IHSGt }- \text { IHSGt-1 }}{\text { IHSGt-1 }}
$$

Keterangan:

$\mathrm{R}_{\mathrm{m}, \mathrm{t}} \quad$ : return pasar saham i pada hari ke $\mathrm{t}$

IHSG $_{\mathrm{t}} \quad$ : Indeks Harga Saham Gabungan pada hari ke $\mathrm{t}$

IHSG $_{\mathrm{t}-1} \quad$ : Indeks Harga Saham Gabungan pada hari ke t-1

3. Menghitung abnormal return

$\mathrm{ARi}, \mathrm{t}=\mathrm{Ri}, \mathrm{t}-\mathrm{Rm}, \mathrm{t}$

Keterangan:

$\mathrm{AR}_{\mathrm{i}, \mathrm{t}} \quad$ : abnormal return saham i pada hari ke $\mathrm{t}$

$\mathrm{R}_{\mathrm{i}, \mathrm{t}} \quad$ : return saham i pada hari ke $\mathrm{t}$

$\mathrm{R}_{\mathrm{m}, \mathrm{t}} \quad$ : return pasar saham i pada hari ke $\mathrm{t}$

4. Menghitung rata-rata abnormal return sebelum dan sesudah stock split

$$
\mathrm{RAR}_{\text {sebelum }}=\sum_{\mathrm{t}=-1}^{-10} \frac{\mathrm{AR}_{\mathrm{i}, \mathrm{t}}}{10} \quad \mathrm{RAR}_{\text {sesudah }}=\sum_{\mathrm{t}=1}^{10} \frac{\mathrm{AR}_{\mathrm{i}, \mathrm{t}}}{10}
$$

Keterangan:

$\mathrm{RAR}_{\text {sebelum }} \quad$ : rata-rata abnormal return saham i sebelum stock split

$\mathrm{RAR}_{\text {setelah }} \quad$ : rata-rata abnormal return saham i setelah stock split

ARi,t : abnormal return saham i pada hari ke $\mathrm{t}$

\section{Trading Volume Activity.}

Adapun cara untuk menghitung trading volume activity dalam penelitian ini adalah:

1. Menghitung trading volume activity

$$
\mathrm{TVA}_{\mathrm{i}, \mathrm{t}}=\frac{\text { Volume perdagangan saham } \mathrm{i} \text { pada hari } \mathrm{t}}{\text { Jumlah saham perusahaan } \mathrm{i} \text { yang beredar pada hari } \mathrm{t}}
$$

Keterangan:

TVAi,t : trading volume activity saham i pada hari ke $\mathrm{t}$

2. Menghitung rata-rata trading volume activity sebelum dan sesudah stock split

$$
\operatorname{RTVA}_{\text {sebelum }}=\sum_{\mathrm{t}=-1}^{-10} \frac{\mathrm{TVA}_{\mathrm{i}, \mathrm{t}}}{10} \quad \text { RTVA }_{\text {sesudah }}=\sum_{\mathrm{t}=1}^{10} \frac{\mathrm{TVA}_{\mathrm{i}, \mathrm{t}}}{10}
$$

Keterangan:

$\mathrm{RTVA}_{\text {sebelum }}$ : rata-rata trading volume activity saham i sebelum stock split

RTVA $_{\text {sesudah }}$ : rata-rata trading volume activity saham i sesudah stock split

TVAi,t : : trading volume activity saham i pada hari ke $\mathrm{t}$

Metode Analisis Data. Sebelum menentukan jenis uji statistik yang digunakan dalam menguji hipotesis, perlu dilakukan uji asumsi dasar yaitu uji normalitas untuk mengetahui apakah data yang digunakan dalam penelitian terdistribusi normal. Uji normalitas dilakukan menggunakan One Sample Kolmogorov-Smirnov Test dengan tingkat signifikansi 0,05. Pengujian hipotesis akan dilakukan dengan bantuan program SPSS 20.0 menggunakan uji Paired Sample T-Test apabila data terdistribusi dengan normal atau dengan menggunakan uji Wilcoxon Signed Ranked Test apabila data tidak terdistribusi dengan normal. Tingkat signifikansi yang digunakan adalah 0,05. 


\section{HASIL DAN PEMBAHASAN \\ Pengujian Normalitas.}

Tabel 1

Uji Normalitas - One Sample Kolmogorov-Smirnov Test

\begin{tabular}{|l|r|r|r|r|}
\hline & \multicolumn{2}{|c|}{ RAR } & \multicolumn{2}{c|}{ RTVA } \\
\cline { 2 - 5 } & \multicolumn{1}{|c|}{ Sebelum } & \multicolumn{1}{c|}{ Sesudah } & Sebelum & \multicolumn{1}{c|}{ Sesudah } \\
\hline $\mathrm{N}$ & 46 & 46 & 46 & 46 \\
Statistic & .089 & .214 & .252 & .271 \\
Sig. & .200 & .000 & .000 & .000 \\
\hline
\end{tabular}

Sumber: data diolah menggunakan SPSS 20.0

Uji normalitas atas data rata-rata abnormal return (RAR) dan rata-rata trading volume activity (RTVA) dilakukan menggunakan One Sample Kolmogorov-Smirnov Test dengan tingkat signifikansi 0,05 . Hasil pengujian pada Tabel 1 menunjukkan bahwa data RAR sebelum memiliki nilai signifikasi $>0.05$ yaitu sebesar 0.200 yang artinya data terdistribusi normal. Sedangkan data $\mathrm{RAR}_{\text {sesudah, }} \mathrm{RAR}_{\text {sebelum }}$ dan $\mathrm{RAR}_{\text {sesudah }}$ memiliki nilai signifikasi $\leq 0.05$ yaitu sebesar 0.000 yang artinya data tidak terdistribusi normal. Oleh sebab itu, maka pengujian hipotesis selanjutnya akan menggunakan metode statistik non parametrik yaitu uji Wilcoxon Signed Ranked Test.

\section{Pengujian Hipotesis Pertama.}

Adapun hipotesis pertama yang akan diuji dirumuskan sebagai berikut:

$\mathrm{H}_{0}$ : Tidak terdapat perbedaan yang signifikan pada abnormal return saham sebelum dan sesudah stock split

$\mathrm{H}_{\mathrm{a}}$ : Terdapat perbedaan yang signifikan pada abnormal return saham sebelum dan sesudah stock split.

Tabel 2

Uji Wilcoxon - Data Rata-Rata Abnormal Return Saham

\begin{tabular}{|c|c|}
\hline \multicolumn{2}{|c|}{ Test Statistics ${ }^{\mathbf{a}}$} \\
\hline & RAR Sebelum - RAR Sesudah \\
\hline $\begin{array}{l}\mathrm{Z} \\
\text { Asymp. Sig. (2-tailed) }\end{array}$ & $\begin{array}{r}-2.72 \phi^{b} \\
.006\end{array}$ \\
\hline $\begin{array}{l}\text { a. Wilcoxon Signed Ranks Test } \\
\text { b. Based on positive ranks. }\end{array}$ & \\
\hline
\end{tabular}

Sumber: data diolah menggunakan SPSS 20.0

Pengujian hipotesis dilakukan menggunakan uji Wilcoxon Signed Ranked Test dengan tingkat signifikansi 0,05. Hasil pengujian menunjukan nilai signifikasi $\leq 0.05$ yaitu sebesar 0.006 . Oleh sebab itu maka $\mathrm{H}_{0}$ ditolak dan dapat disimpulkan bahwa terdapat perbedaan yang signifikan pada abnormal return saham sebelum dan sesudah stock split. Penelitian ini sesuai dengan penelitian sebelumnya yang dilakukan oleh Muharam dan Sakti (2008), Safitri dan Widjanarko (2009), Rusliati dan Farida (2010) dan Hernoyo (2013) namun tidak sesuai dengan penelitian sebelumnya yang dilakukan oleh Akhmad dan Ramadiyansari (2013) dan Asriningsih (2015). 
Hasil pengujian ini sesuai dengan Signalling Theory yang menyatakan bahwa corporate action merupakan pemberian sinyal yang positif kepada investor bahwa kinerja perusahaan kedepannya diyakini akan terus meningkat dan memberikan return yang menguntungkan, stock split yang dilakukan oleh perusahaan diinterpretasikan oleh investor sebagai sinyal positif yang ditandai dengan munculnya abnormal return di sekitar tanggal pengumuman stock split.

Selanjutnya, fenomena munculnya abnormal return menunjukkan bahwa Bursa Efek Indonesia merupakan kategori pasar efisien bentuk lemah dikarenakan masih adanya informasi publik yang memberikan peluang bagi para investor untuk mendapatkan abnormal return. Apabila pasar efisien bentuk setengah kuat terpenuhi, idealnya tidak akan ada abnormal return yang terjadi dari hasil pemanfaatan informasi publik.

\section{Pengujian Hipotesis Kedua.}

Adapun hipotesis kedua yang akan diuji dirumuskan sebagai berikut:

$\mathrm{H}_{0}$ : Tidak terdapat perbedaan yang signifikan pada likuiditas saham sebelum dan sesudah stock split

$\mathrm{H}_{\mathrm{a}}$ : $\quad$ Terdapat perbedaan yang signifikan pada likuiditas saham sebelum dan sesudah stock split.

Tabel 3

Uji Wilcoxon - Data Rata-Rata Trading Volume Activity

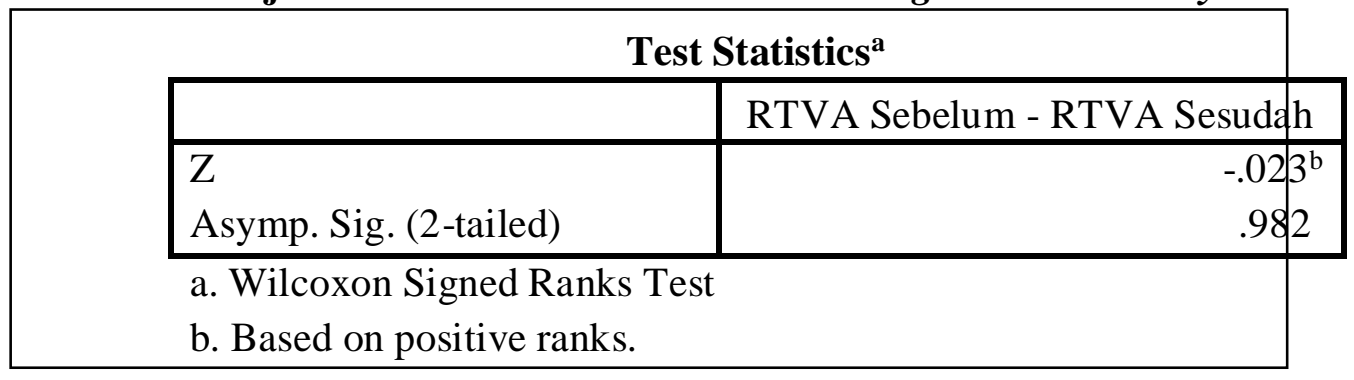

Sumber: data diolah menggunakan SPSS 20.0

Pengujian hipotesis dilakukan menggunakan uji Wilcoxon Signed Ranked Test dengan tingkat signifikansi 0,05 . Hasil pengujian menunjukan nilai signifikasi $>0.05$ yaitu sebesar 0.982 . Oleh sebab itu maka $\mathrm{H}_{0}$ diterima dan dapat disimpulkan bahwa tidak terdapat perbedaan yang signifikan pada likuiditas saham sebelum dan sesudah stock split. Penelitian ini sesuai dengan penelitian sebelumnya yang dilakukan oleh Muharam dan Sakti (2008) dan Hernoyo (2013) namun tidak sesuai dengan penelitian sebelumnya yang dilakukan oleh Safitri dan Widjanarko (2009), Akhmad dan Ramadiyansari (2013) dan Asriningsih (2015).

Hasil pengujian ini tidak mendukung Trading Range Theory yang menyatakan bahwa stock split digunakan sebagai alat untuk mengatur kembali harga saham pada kisaran yang diinginkan oleh perusahaan sehingga dapat meningkatkan likuiditas perdagangan saham. Adapun penyebab dari ketidaksesuaian antara teori dengan hasil penelitian ini dapat disebabkan oleh beberapa hal sebagai berikut:

1. Selain harga saham, terdapat berbagai faktor lain yang dapat mempengaruhi likuiditas saham suatu perusahaan, misalkan faktor ekonomi makro seperti adanya kenaikan tingkat suku bunga dan faktor internal berupa kinerja perusahaan itu sendiri.

2. Periode pengamatan (event period) yang digunakan dalam penelitian ini tergolong cukup singkat yaitu hanya selama 20 hari. Tidak menutup kemungkinan bahwa singkatnya 
periode pengamatan tersebut belum sepenuhnya dapat mengakomodir efek dari stock split terhadap likuiditas saham.

\section{PENUTUP}

Kesimpulan. Berdasarkan pengujian hipotesis yang sudah dilakukan sebelumnya, dapat disimpulkan bahwa dengan tingkat keyakinan $95 \%$ terdapat perbedaan yang signifikan pada abnormal return saham sebelum dan sesudah stock split pada perusahaan yang terdaftar di Bursa Efek Indonesia periode 2010-2015 dan tidak terdapat perbedaan yang signifikan pada likuiditas saham sebelum dan sesudah stock split pada perusahaan yang terdaftar di Bursa Efek Indonesia periode 2010-2015.

Saran. Bagi investor, diharapkan agar hasil penelitian ini dapat memberikan tambahan informasi bahwa aktivitas stock split masih memberikan peluang untuk mendapatkan abnormal return. Bagi perusahaan, diharapkan agar hasil penelitian ini dapat memberikan tambahan informasi bahwa stock split tidak serta merta langsung meningkatkan likuiditas saham, selain penurunan harga saham perlu dipikirkan cara lain untuk menggairahkan perdagangan saham misalkan dengan senantiasa menunjukkan kinerja yang baik. Bagi penelitian selanjutnya, diharapkan agar dapat memperpanjang periode pengamatan (event period) untuk mendeteksi efek dari stock split terhadap likuiditas saham dalam jangka panjang.

\section{DAFTAR PUSTAKA}

Akhmad, Arifin dan Ramadiyansari, Rika. (2013). Analisis Perbandingan Abnormal Return, Volume Perdagangan Saham dan Likuiditas Sebelum dan Sesudah Stock Split Pada Perusahaan Manufaktur Yang Terdaftar di Bursa Efek Indonesia. Jurnal Ekonom, 16 (1), 19-29.

Asriningsih, Wening. (2015). Analisis Abnormal Return dan Likuiditas Saham Sebelum dan Sesudah Stock Split Periode 2008-2012. Jurnal Economia, 11 (1), 10-15.

Copeland, T.E. (1979). Liquidity Following Stock Split. Journal of Finance, 34(1), 115-141. Ewijaya dan Indriantoro, Nur. (1999). Analisis Pengaruh Pemecahan Saham Terhadap Perubahan Harga Saham. Jurnal Riset Akuntansi Indonesia, 2 (1), 53-64.

Hernoyo, Muhammad A. (2013). Pengaruh Stock Split Announcement Terhadap Volume Perdagangan dan Return. Management Analysis Journal, 2 (1), 110-116.

Hikmah, Khoirul dan Satoto, Shinta Heru. (2010). Analisis Tingkat Kemahalan Harga Saham dan Kinerja Keuangan Perusahaan Sebagai Faktor Pembeda Keputusan Pemecahan Saham (Stock Split): Pengujian Terhadap Trading Range Hypothesis dan Signaling Hypothesis. Buletin Ekonomi, 8 (1), 23-31.

Horne, Van J. dan Wachowicz, John M. (2005). Fundamentals of Financial Management ( $8^{\text {th }}$ ed). New Jersey: Prentice-Hall International Edition.

Jogiyanto. (2008). Teori Portofolio dan Analisis Investasi (Edisi ketiga). Yogyakarta: BPFE.

Jogiyanto. (2014). Studi Peristiwa: Menguji Reaksi Pasar Modal Akibat Suatu Peristiwa. Edisi Pertama.Yogyakarta: BPFE.

Muharam, Harjum dan Sakti, Hanung. (2008). Analisis Perbedaan Liquiditas Saham, Kinerja Keuangan, dan Return Saham di Sekitar Pengumuman Stock Split. Journal The Winners, 9 (1), 1-21.

Rusliati, Ellen dan Farida, Esti Nur. (2010). Pemecahan Saham Terhadap Likuiditas dan Return Saham. Jurnal Bisnis dan Akuntansi, 12 (3), 161-174.

Safitri, Diyah dan Widjanarko, Hendro. (2009). How Does Globalization Imply Trading Volume Activity and Abnormal Return Before and After Stock Split. Jurnal Bisnis dan Akuntansi Universitas Pembangunan Nasional "Veteran", 1 (1), 1-15. 
Savitri, Melinda dan Martani, Dwi. (2006). The Analysis Impact of Stock Split and Reverse Stock Split on Stock Return and Volume: The Case of Jakarta Stock Exchange. Jurnal Akuntansi Universitas Indonesia, 1-16.

Winarso, Beni S. (2005). Analisis Empiris Perbedaan Kinerja Keuangan Antara Perusahaan yang Melakukan Stock Split dengan Perusahaan yang Tidak Melakukan Stock Split: Pengujian The Signaling Hypotesis. Jurnal Akuntansi dan Manajemen, 16(3), 209-218. 
